\section{CONTAGENS \\ DIFERENCIAIS \\ DE \\ PROTOZOÁRIOS CILIADOS EM RÚMEN DE \\ BOVINOS ARRAÇOADOS COM CAPIM \\ ELEFANTE NAPIER (Pennisetum purpureum SCHUM), EM VÁRIOS ESTÁDIOS DE CRESCIMENTO VEGETATIVO}

\section{JOSE CARLOS MACHADO NOGUEIRA FILHO}

Professor Doutor

Faculdade de Medicina Veterinária e Zootecnia da USP

\section{CARLOS DE SOUZA LUCCI}

Professor Titular

Faculdade de Medicina Veterinária e Zootecnia da USP

LAÉRCIO MELOTTI

Professor Doutor

Faculdade de Medicina Veterinária e Zootecnia da USP

\section{MARLA ELY MISEROCHI DE OLVEIRA}

Professor Doutor

Instituto de Ciencias Biomédicas da USP

CESAR GONÇALVES DE UMA

Professor Assistente

Faculdade de Modicina Veterinária e Zootecnia da USP

\section{JOSÉ APARECIDO DA CUNHA}

Tócnico Especializado

Faculdade de Medicina Veterinária • Zootecnia da USP

NOGUEIRA FILHO, J.C.M.; LUCCI, C.S.; MELOTTI, L.; OLNEIRA, M.E.M.; LIMA, C.G.; CUNHA, J.A Contagens diferenciais de protozoários ciliados em rúmen de bovinos arraçoados com capim elefante Napier (Pennisetum purpureum Schum), om vários estádios de crescimento vegetativo. Braz. J. vet Res. anim. Scl.. Săo Paulo, v.29, n.2, p.215-21, 1992.

RESUMO: Capim elefante Napier (Pennisetum purpuroum Schum) colhido em quatro estédios de desenvolvimento: a) $1,30 \mathrm{~m}$ de altura e $17,54 \%$ de materia seca; b) $2,35 \mathrm{~m}$ de altura - 25,84\% de matória seca; - c) $3,25 \mathrm{~m}$ de attura e $26,31 \%$ de materia seca, foi fornecido "ad libitum" a 8 bovinos com $5 / 8$ de sangue europeu-zebu, com $220 \mathrm{~kg}$ de peso vivo médio, providos de fístulas ruminais. Todos receberam $1,5 \mathrm{~kg}$ de uma mistura concentrada com $24,10 \%$ de proteína bruta. Os tratamentos foram comparados em um delineamento inteiramente casualizado, sendo que na quarta semana de cada periodo experimental colheram-se amostras de liquido de rúmen antes da oferta dos alimentos, para contagens diferenciais dos seguintes gêneros de protozoários ciliados e auferir suas concentraços por milititro: Entodinlum spp; Diplodinlum spp; Eudlplodinlum spp a Polyplastron spp. Os resultados mostraram que os protozoários ciliados do gênero Entodinium predominaram com $96,73 \%$ do total da populaçăo desses microorganismos. O número de Entodinlum spp decresceu com a maturaçăo da planta: a) $18,2 \times 10^{4} / \mathrm{ml}$; b) 12,1 $\times 10^{4} / \mathrm{ml}$; c) $9.8 \times 10^{4} / \mathrm{ml}$.

UNITERMOS: Rúmen, microbiota; Protozóários; Nutriçăo, ruminantes; Bovinos

\section{INTRODUÇAO}

A populaçáo microbiana no rúmen e caracterizada por diversas espécies de bacterias e protozóários. Embora os tipos de unicelulares no rúmen sejam relativamente estáveis devido as condiçoes de meio ambiente naquele compartimento, as proporços das várias especies podem ser influenciadas pelo tipo de alimento da dieta, pola qualidade da forragem volumosa, e pola especie de ruminante.

Dietas de forragens podem variar extensivamente na disponibilidade de sous nutrientes para o uso microbiano. A maior parte da energia em dietas com volumosos está na forma de carboidratos estruturais presentes na parede celular da planta, a qual atacada, concomitantemente, por bactérias o protozotrios ciliados. Entre os protozónios, os da especie Epidinium ecaudatum parecem ser mais eficientes no ataque $\theta$ ingestão de paredes celulares de plantas forrageiras (AKIN '. 1981). Este autor, admite que a anatomia das laminas dos volumosos e os tipos de tecidos que os constituem influenciam a degradaçăo microbiana, devido a maior ou menor presença de celulose, hemicolulose, lignina e ácidos fenólicos, e conclu que a digestă de forragens resulta de uma complexa interaçăo dos microorganismos do rúmen com a estrutura da parede colular da planta.

HUNGATE ${ }^{8}$ (1966) salienta que protozó́rios Holotricha surgem em grande número no rúmen de animais em regime de pastejo, ou em dietas contendo quantidades consideráveis de feno, ao passo que os Diplodinium spp nunca săo detectados em quantidades maciças, tanto em animais ingerindo elevadas quantidades de grảos, como naqueles submetidos a condiços de pastejo ou apascentados com feno.

QUINN ot al. 17 (1962) asseguraram que ciliados Entodinium spp parecem estar dependentes de uma fonte de celulose e amido na dieta.

OUVEIRA ot al. 14 (1987), trabahando com líquido ruminal colhido de ovinos manejados exclusivamente em pastagens, verificaram que as especies de Entodinlum e Diplodinium, perfizeram $92,3 \%$ do total de protozórios ciliados detectados. Quando trabalharam com bezerros da raça 
Conragens diferenciess de prorarainos cilledos em nimen.

Holandesa e do tipo Mantiqueira, arracoados com pequenas quantidades de concentrados e feno, e pasto à vontade. NOGUEIRA FILHO ot al. ${ }^{12,13}$ (1983, 1984) observaram que os generos acıma mencionados constituiram mais de $90 \%$ do total de ciliados.

Estudos lovadus a efeito por NAKAMURA e KANEGASAKI 10 (1969), com ovinos. demonstraram a influência do tipo de raçäo sobre as concentraçōes de protozoários ciliados. Um amplo decréscimo no número de ciliados foi observado $(2-4 \times$ $10^{5} / \mathrm{ml}$ ) quando a dieta era somente de feno de graminea, enquanto com uma raçào contendo concentrado mais feno de graminea a populaçāo de ciliados variou de $7-12 \times 10^{5} / \mathrm{ml}$. Já os dados auferidos por GRUBB e DEHORITY ${ }^{7}$ (1975), também com ovinos, revelaram números de protozóários ciliados de $4-6$ $\times 10^{5} / \mathrm{ml}$, quando os animais estavam em um tratamento somente com feno de graminea. e de $10.18 \times 10^{5} / \mathrm{ml}$ quando submetidos a uma dieta com $60 \%$ de milho e $40 \%$ de volumoso.

Por outro lado, com base em observaçóes conduzidas por BRYANT O SMALL ${ }^{2}$ (1960); EADIE ${ }^{5}$ (1962); HUNGATE ${ }^{8}$ (1966); PURSER \& MOIR 16 (1966); NOGUEIRA FIUHO 11 (1981); NOGUEIRA FIUHO et al. ${ }^{12,13}$ (1983, 1984): DEHORITY 4 (1987); OUVEIRA ot al. ${ }^{14}$ (1987). $\mathrm{pH}$ do líquido ruminal parece ser importante no estabelecimento e permanencia dos protozodrios ciliados no rúmen.

O presente trabalho procurou estudar a ocorrencia nas variaçoses de populaçóes de protozoários ciliados, quando o mesmo capim elefante Napier foi oferecido em estádios vegetativos diferentes, junto com porģăo de 1,5 kg de mistura concentrada por animal o por dia.

\section{MATERIAL E MÉTODO}

O experimento em pauta foi conduzido na Faculdade de Medicina Veterinária e Zootecnia da Universidade de Săo Paulo, Campus de Pirassununga, SP, situado a $21^{\circ} 8$ ' de latitude sul $\theta$ $47^{\circ} 25$ '42" de longitude oeste, com altitude de 634 metros.

O clima da regiảo, segundo classificaçăo de Koeppen (OMETTO 15, 1981), a do tipo Cwa, isto 6, temperado chuvoso com inverno seco e verăo quente chuvoso, típico de subtropical.

Foram trabalhadas amostras de capim elefante Napier (Pennleotum purpuroum Schum), colhidas em tres estádios de crescimento vegetativo, a saber:

a) I estádio - altura de $1,30 \mathrm{~m}$ e matéria seca a $65^{\circ} \mathrm{C}$ igual a $17.54 \%$. Período compreendido entre 01/02/88 a 28/02/88.

b) II estádio - altura de $2,35 \mathrm{~m}$ e matéria seca a $65^{\circ} \mathrm{C}$ igual a $25,84 \%$. Período compreendido entre $29 / 02 / 88$ a 27/03/88.

c) III estádio - altura de $3,25 \mathrm{~m}$ e matéria seca a $65^{\circ} \mathrm{C}$ igual a 26.31\%. Periodo compreendido entre 28/03/88 a 24/04/88.
O capim era picado e fornecido a oito bovinos providos de fistulas ruminais, machos castrados, $\infty \mathrm{m} 5 / 8$ de sangue europeu-zebu, com idades aproximadas de 14 meses, $220 \mathrm{~kg}$ de peso vivo médio e portes semelhantes.

Os consumos medios do capim elefante Napier foram de $15.45 \mathrm{~kg}$ (17.54\% de materia seca); $11.03 \mathrm{~kg}$ (25.84\% de materia seca); e $10.50 \mathrm{~kg}(26,31 \%$ de matéria seca) por cabeça $\theta$ por dia, respectivamente para os pericdos $I_{1} \|$ I III. Junto com o volumoso foram fornecidos $1.5 \mathrm{~kg}$ por animal e por dia, durante os 3 períodos, da seguinte mistura concentrada: fubá de milho - 29,20\%; farelo de algodảo - 29,20\%; farelo de soja - $19,86 \%$; farelo de trigo - $19.86 \%$; sal mineral - $1.88 \%$, compondo uma raçảo concentrada de $24.16 \%$ de proteína bruta.

Amostras de líquido de rúmen foram colhidas antes da oferta dos alimentos e da administraçăo do polietilenoglicol (PEG-4.000 F), na última semana de cada periodo, diretamente do rúmen, através de bomba de sucçăo. 0 marcador da fase líquida do rúmen (PEG-4.000 F) foi administrado na base de 50 . 80 e $100 \mathrm{~g}$, respectivamente para os períodos I, II e III, com o propósito de se estudarem volume e "tum-over" do líquido ruminal (HYDEN ${ }^{9}, 1956$ ). Antes da colocachlo do PEG-4.000 F. colhiam-se 30 a $40 \mathrm{ml}$ de fluido ruminal que oram recobidos om um balăo kitasato, $\theta$ uma alíquota de $10 \mathrm{ml}$, transferida para um tubo de ensaio $\infty \mathrm{m} 20 \mathrm{ml}$ de formadeído (diluído em água destilada a 1:2); o tubo era agitado imediatamente após a colheita, para fixaçăo dos protozoários. $\mathrm{O} \mathrm{pH}$ da amostra foi medido no momento da colheita do líquido de rúmen. utilizando-se peagâmetro digital portátil.

As amostras permaneciam om repouso por uma noite, sendo depois diluidas a 1:20 em soluçāo de glicerol a $30 \%$, em água destilada. O verde brilhante" foi o corante utilizado, consoante DEHORITY ${ }^{3}$ (1977).

Um $\mathrm{ml}$ do material foi transferido para uma camara de Sedgwick-Rafter, para contagem diferencial dos gêneros, conforme DEHORITY ${ }^{3}$ (1977)

A análise estatística foi feita por delineamento inteiramente casualizado (GOMES 6,1970 ), com 3 tratamentos (períodos de crescimento vegetativo do capim) e 8 repetiços por tratamento, transformando-se os dados em $\sqrt{x+0}$, dentro do seguinte esquema:

CAUSAS DE VARIAÇAo GRAUS DE UBERDADE

\begin{tabular}{lc}
\hline Tratamentos & 2 \\
Rogressão linear & 1 \\
Desvios da regressão & 1 \\
Resíduo & 21 \\
\hline Total & 23 \\
\hline
\end{tabular}


RESULTADOS E DISCUSSẢO

A Tab. 1 mostra os resultados obtidos segundo as contagens por mililitro de líquido ruminal, para os seguintes protozóarios ciliados. número total, Entodinium spp: Diplodinium spp: Eudiplodinium spp e Polyplastron spp

A varıaçăo do número de protozoários totass por mililitro. constituido em sua maioria por Entodinlum $\operatorname{spp}(96,73 \%)$, bem como do número de Entodinlum spp por mililitro. mostrou uma queda linear altamente significativa $(p<0.01)$, com 0 avançar do crescimento vegetativo do capim. O desenho traçado da regressão, obtido para protozoários totais e Entodinium spp por $\mathrm{ml}$ de líquido ruminal, pode ser visto nas Fig. 1 e 2 .

Tamberm foram encontrados decréscimos significativos no número de Diplodinium spp e Polyplastion spp. O predomínio quase absoluto do gênero Entodinium já foi acusado em outros trabalhos nacionais (NOGUEIRA FILHO et al. 12,13, 1983, 1984; OLIVEIRA et al. $\left.{ }^{14}, 1987\right)$.

Por outro lado, as médias das concentraçóes de protozoarios ciliados encontradas sảo superiores às acusadas para dietas com feno apenas (20.000 a $40.000 / \mathrm{ml})$, conforme NAKAMURA e KANEGASAKI ${ }^{10}$ (1969), embora com feno mais concentrados os mesmos autores tivessem atingido valores de 70.000 a $120.000 / \mathrm{ml}$, próximos aos deste trabalho. GRUBB e DEHORITY ${ }^{7}$ (1975) indicam valores de 100.000 a $180.000 / \mathrm{ml}$ quando em dietas com $60 \%$ de concentrados e $40 \%$ de volumosos.

A diminuiçảo do número total de protozoários e de Entodinium spp por mililitro pode ser explicada pela diminuição de açúcares solúveis e aumento da fibra, com o crescimento do capim em períodos sucessivos. Com dietas mass fibrosas, provaveimente tenha ocorrido major retençăo de matéria seca no rúmen e conseqüente decréscimo na pcpulaçăo de ciliados

Os valores de pH encontrados foram de 6.88; 6.67; e 6.49, respectivamente para os tratamentos $a, b$ e c

Outro aspecto a ser considerado a o do número de protozoários ciliados no volume líquido total do rúmen. Com o emprego do marcador PEG-4.000 F, foi possivel estimar o volume de líquido no rúmen dos animais, e a Tab. 2 fornece o número de protozodrios no total do conteúdo ruminal.

\section{CONCLUSÓES}

Nas condiçes do presente experimento, as seguintes conclusões podem ser enumeradas

1. houve decréscimo linear no número de Entodinlum spp. Diplodinium spp e Polyplastron spp. por mililitro de líquido rumınal. com o avançar da idade da planta forrageira;

2. houve decréscimo linear no número total de protozoários por mililitro de líquido ruminal, com o avançar da idade da planta forrageira.
NOGUEIRA FILHO, J.C.M.; LUCCI. C.S.; MELOTTI, L.: OLNEIRA. M.E.M.; LIMA, C.G.: CUNHA, J.A Differencial rumen protozoa counting from steers fed Napier elephant grass (Pennisetum purpureum Schum) at different maturity stages Braz. J. vet. Res. anim. Sci. Sảo Paulo, v.29. n.2. p.215-21. 1992

SUMMARY: Napier grass (Pennisetum purpureum Schum) in 3 growing stages: a) $1.30 \mathrm{~m}$ tall and $17.54 \%$ dry matter; b) $2.35 \mathrm{~m}$ tall and $25.84 \%$ dry matter; and c) $3.25 \mathrm{~m}$ tall and $26.31 \%$ dry matter, was fed "ad libitum" to eight pumen fistulated steers all crossbred (5/8 european-zebu) weighting $220 \mathrm{~kg}$, being fed 1,5 $\mathrm{kg}$ or a concentrate meal with $24.16 \%$ of crude protein. Treatments were compared in a completely randonmized design using the $4^{\text {th }}$ week of each experimental period for rumen liquor sampling for differencial counts of the following protozoa: Entodinium, Diplodinium, Eudiplodinium and Polyplastron. Results showed Entodinium as $96.73 \%$ of total protozoa and its concentration per mililiter of rumen fluid decreased linearly as the plant matured $\left(a=18.2 \times 10^{4} / \mathrm{ml} ; \mathrm{b}=\right.$ $12.1 \times 10^{4} / \mathrm{ml}$; and $\mathrm{c}=9.8 \times 10^{4} / \mathrm{ml}$ ).

UNITERMS: Rumen, microbiology; Protozoa; Nutrition of ruminants; Cattle

\section{REFERÊNCIAS BIBLIOGRÁFICAS}

01-AKIN, D.E. Microbial breakdown of feed in the digestive tract. In: HACKER, J.B., ed. Nutritional limits to animal production from pastures. Oueensiand, Commonwealth Agricultural Bureaux. 1981, p.201-23.

02-BRYANT, M.P.; SMALL, N. Observations on the ruminal microorganisms of isolated and inoculated calves. $\mathrm{J}$. Dairy Sei., v.43, p.654-67, 1960.

03-DEHORITY, B.A. Claselfication and morphology of rumen protozoa. Wooster, Ohio Agricultural Research and Development Center, 1977

04DEHORITY, B.A. Rumen microblology. Wooster, Onio Agricultural Research and Development Center, 1987.

05-EADIE, J.M. The development of rumen microbial populations in lambs and calves under various conditions of management. J. gen. Microbiol., v.29, p.563-78. 1962

06-GOMES, F.P. Curso de estatística experimental Piracicaba, Nobel, 1970. 
Contegens diterencies de propozoinas cilledos om rimen

07-GRUBB, J.A; DEHORITY, B. Effects of an abrupt change in ration from all roughage to high concentrate upon rumen microbial numbers in sheep. Appl. Microbiol., v.30, p.402-12, 1975.

08-HIJNGATE, RE. The rumen and its microbes. New York, Academic Press, 1966.

09-HYDEN, S. A turbidometric method for the determination of higher polyethylene glycols in biological material. kgl. Lantbruks hogskol. Ann., v.22, p.139-45, 1956.

10-NAKAMURA, K.; KANEGASAKI, S. Densities of ruminal protozoa of sheep established under different dietary conditions. J. Dairy Sel., v.52, p.250-5, 1969.

11-NOGUEIRA FILHO. J.C.M. Contribuiçāo ao estudo sobre protozotrios em rúmen de bezerros de rebanhos leitelros. Sảo Paulo, 1981. Dissertaçăo (Mestrado) Faculdade de Medicina Veterinária e Zootecnia, Universidade de Sảo Paulo.

12-NOGUEIRA FILHO, J.C.M.; OLIVEIRA, M.E.M.; VEIGA, J.S.M.; LUCCI, C.S. Observaçōes pertinentes à instalaçăo da fauna de protozoários ciliados no rúmen de bezerros da raça Holandess. (Bos teurus L) criados em Pindamonhangaba, S. Paulo, Brasil. Rev. Fac. Med. Vet Zootec. Univ. S. Paulo, v.20, p.177-B2, 1983.
13-NOGUEIRA FILHO, J.C.M.; OLIVEIRA, M.E.M.; VEIGA, J.S.M.; LUCCI, C.S. Cronologia do aparecimento de protozoários ciliados no rúmen de bezerros do upo "Mantiqueira" (Bos taurus L.), na região do Vale do Rio Paraiba, SP, Brasil. Rev. Fac. Mod. Vet Zootec. Univ. S. Paulo, v.21, p.119 24, 1984 .

14-OLIVEIRA, M.E.M.; NOGUEIRA FILHO, J.C.M.: LUCCI, C.S.; DUPAS, W.; LIMA, C.G. Desenvolvimento de populaçōes de protozoários ciliados no rúmen de ovinos (Ovis aries L.), criados em Itapetininga, Sảo Paulo. Rev. Fac. Med. Vot Zootoc. Univ. S. Paulo, v.24, p.225-32, 1987.

15-OMETTO, J.C. Bioclimatologia vegetal. São Paulo, Agronômica Cores, 1981.

16-PURSER, D.B.; MOIR, R.J. Dietay effects uppon concentrations of protozoa in the rumen. J. anim. Scl., v.25, p.663-74, 1966

17-OUINN, LY.; BURROUGHS, W.; CHRISTLANSEN, W.C. Continuous culture of ruminal microorganisms in chemically defined medium. II. Culture medium studies. Appl. Microbiol., v.10, p.583-92, 1962. 
TABELA 1 - Número de protozoários ciliados por mililitro de líquido ruminal, segundo o estádio vegetativo do capim elefante Napier. Pirassununga, 1992.

\begin{tabular}{|c|c|c|c|c|c|c|}
\hline Tratamento & $\begin{array}{c}\text { Consumo MS/animal/ } \\
\text { dia (Kg)* }\end{array}$ & Total/ML & Entodinium spp & Diplodinium spp & Eudiplodinium spo & Polyplastron \\
\hline 1 & 2.71 & 187.274 & 182.139 & 3.338 & 743 & 1.053 \\
\hline II & 2,85 & 126.758 & 120.799 & 4.027 & 972 & 959 \\
\hline 111 & 2,76 & 100.757 & 98.312 & 1.675 & 486 & 284 \\
\hline Média final & . & 138.263 & 133.750 & 3.013 & 734 & 766 \\
\hline C.V. (\%) & & 36.1 & 37.3 & 40.0 & 64.0 & 42.2 \\
\hline & & R.L.\# & R.L.** & R.L.* * & N.S. & R.L."* \\
\hline
\end{tabular}

Obs.: R.L."* = Regressāo linear $(P \leqslant 0,01)$

N.S. = Não significativo

C.V. = Coeficiente de variaçăo

- = Consumo de capim Napier, base seca

TABELA 2 - Volume ruminal (litros) e número de protozoários ciliados no volume líquido total do rúmen. Pirassununga, 1992.

\begin{tabular}{|c|c|c|c|}
\hline Animal $n^{2}$ & I Perf́odo & 11 Per fodo & III Período \\
\hline 590 & $\begin{array}{l}\text { V.R. }=3,79 \\
8,42 \times 10^{8}\end{array}$ & $\begin{array}{l}\text { V.R. }=5,85 \\
6,25 \times 10^{8}\end{array}$ & $\begin{array}{l}\text { V.R. }=13,58 \\
17,07 \times 10^{8}\end{array}$ \\
\hline 571 & $\begin{aligned} & \text { V.R. }=5,00 \\
& 16,80 \times 10^{8}\end{aligned}$ & $\begin{aligned} & \text { V.R. }=7,59 \\
& 10,83 \times 10^{8}\end{aligned}$ & $\begin{array}{l}\text { V.R. }=19,41 \\
19,62 \times 10^{8}\end{array}$ \\
\hline 552 & $\begin{array}{l}\text { V.R. }=3,91 \\
9,12 \times 10^{8}\end{array}$ & $\begin{aligned} & \text { V.R. }=7,33 \\
& 11,82 \times 10^{8}\end{aligned}$ & $\begin{array}{l}\text { V.R. }=14,79 \\
19,40 \times 10^{8}\end{array}$ \\
\hline 573 & $\begin{array}{l}\text { V.R. }=3,37 \\
3,83 \times 10^{8}\end{array}$ & $\begin{array}{l}\text { V.R. }=10,33 \\
11,76 \times 10^{8}\end{array}$ & $\begin{array}{l}\text { V.R. }=17,88 \\
12,31 \times 10^{8}\end{array}$ \\
\hline 1077 & $\begin{array}{l}\text { V.R. }=5,02 \\
5.63 \times 10^{8}\end{array}$ & $\begin{aligned} & \text { V.R. }=10,11 \\
& 11,22 \times 10^{8}\end{aligned}$ & $\begin{array}{l}\text { V.R. }=24,21 \\
15,90 \times 10^{8}\end{array}$ \\
\hline 583 & $\begin{array}{l}\text { V.R. }=3,06 \\
4,04 \times 10^{8}\end{array}$ & $\begin{array}{l}\text { V.R. }=6,35 \\
8,99 \times 10^{8}\end{array}$ & $\begin{array}{l}\text { V.R. }=14,64 \\
12,70 \times 10^{8}\end{array}$ \\
\hline 557 & $\begin{array}{l}\text { V.R. }=2,98 \\
3,76 \times 10^{8}\end{array}$ & $\begin{array}{l}\text { V.R. }=8,50 \\
9,40 \times 10^{8}\end{array}$ & $\begin{array}{l}\text { V.R. }=15,57 \\
20,45 \times 10^{8}\end{array}$ \\
\hline 1080 & $\begin{array}{l}\text { V.R. }=2,92 \\
6,50 \times 10^{8}\end{array}$ & $\begin{array}{l}\text { V.R. }=11,31 \\
14,23 \times 10^{8}\end{array}$ & $\begin{array}{l}\text { V.R. }=13,86 \\
13,06 \times 10^{8}\end{array}$ \\
\hline
\end{tabular}

V.R. = Volume ruminal em litros 


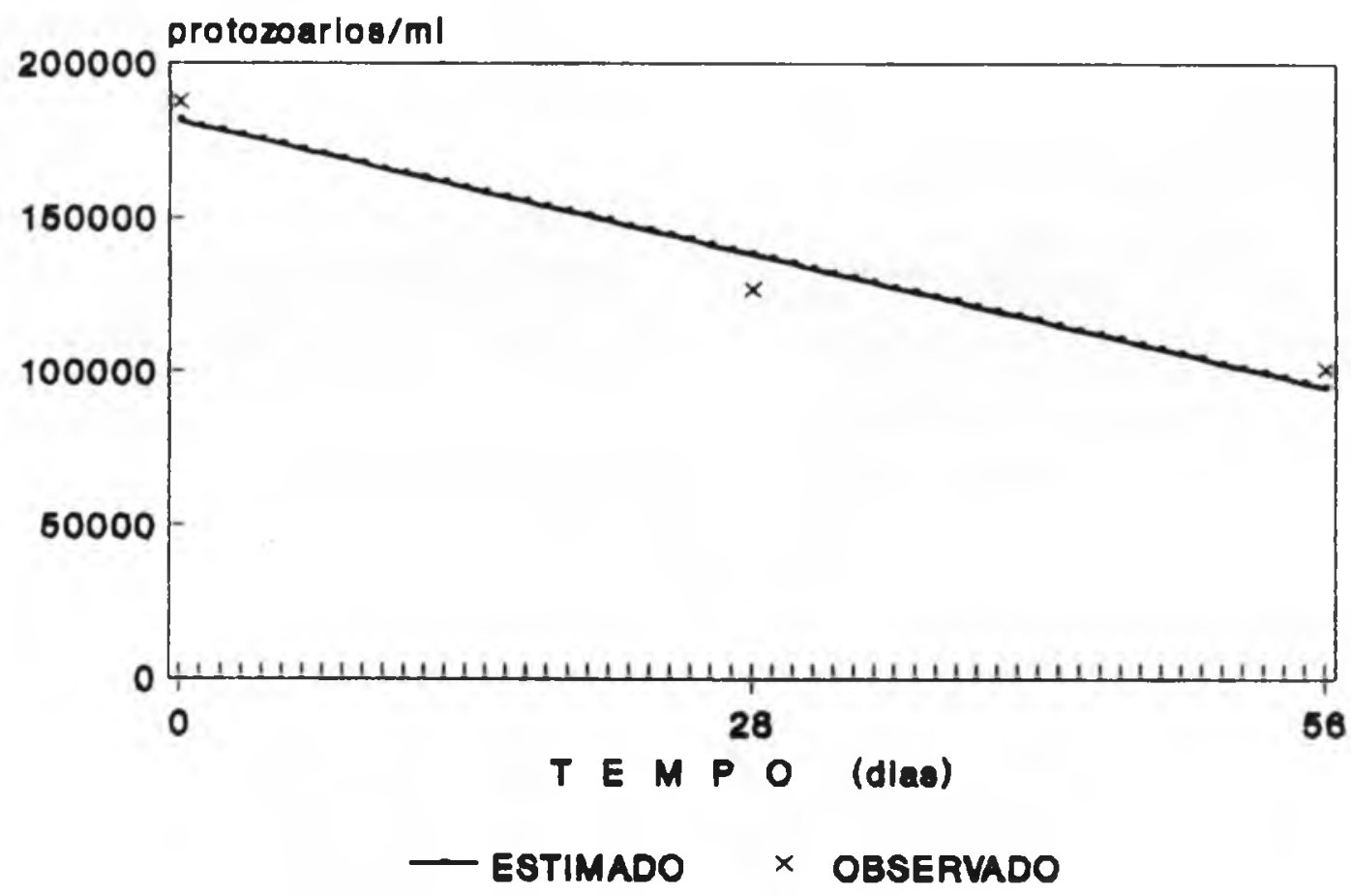

FIGURA 1 - Regressåo linear obtida para protozoários totais por mililitro de líquido do rúmen. Pirassununga, 1992. 

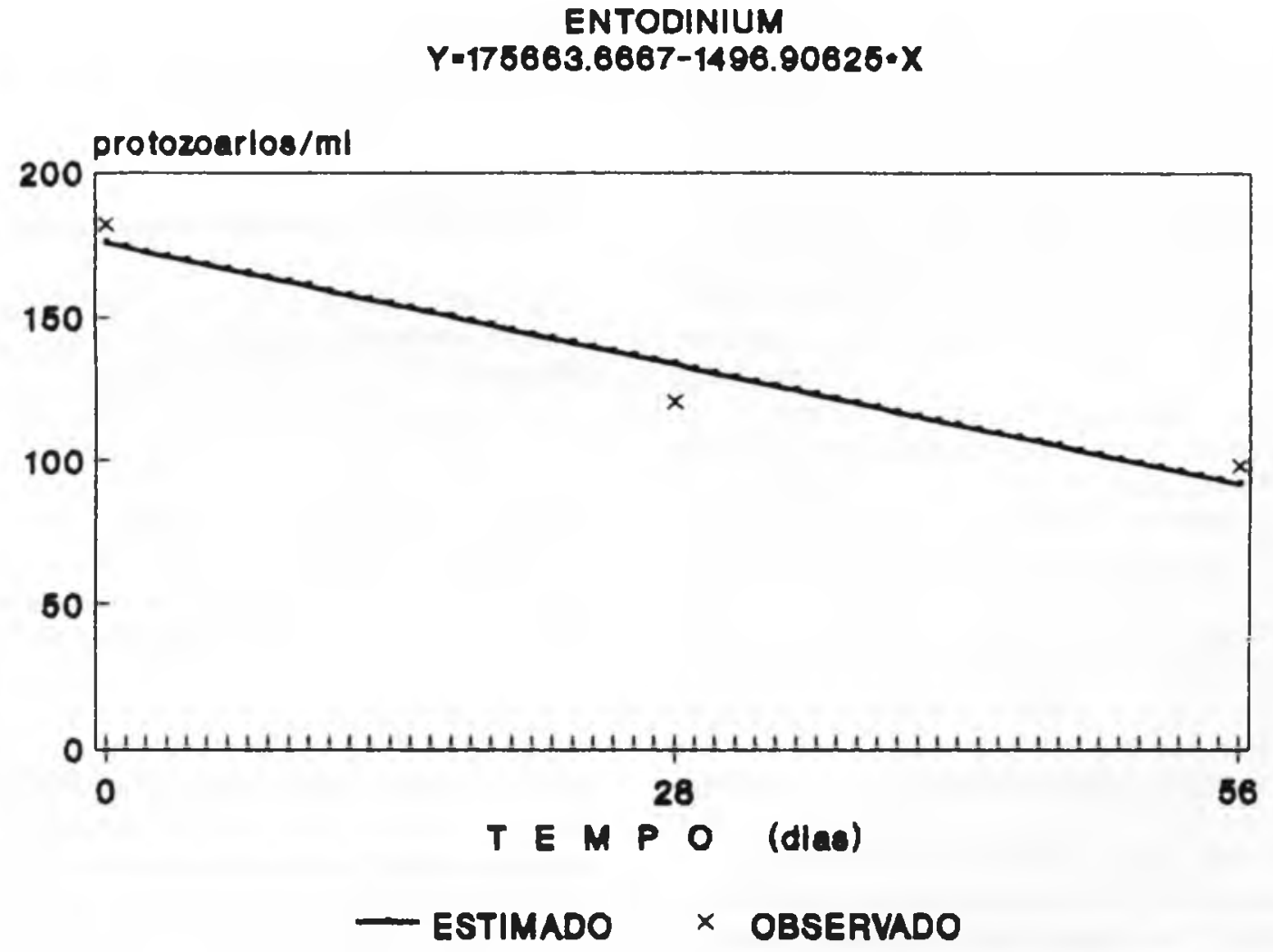

FIGURA 2 - Regressăo linear obtida para Entodinlum spp por mililitro de liquido de rúmen. Pirassununga, 1992. 